\title{
A posição da câmera fotográfica influencia no cálculo computadorizado da área de úlcera por pressão?

\author{
Inalda Leite Pereira ${ }^{1}$ \\ Levy Aniceto Santana ${ }^{2}$ \\ Renato da Veiga Guadagnin ${ }^{3}$
} Luciene Carvalho de Sousa ${ }^{1}$ \\ Recebido em: 26/06/2011 \\ Aceito em: 16/11/2011 Rinaldo de Souza Neves ${ }^{4}$
}

A análise de área de úlcera por pressão através do processamento computacional de imagens vem sendo utilizada como meio de se quantificar a evolução e as respostas de feridas aos tratamentos aplicados. Este artigo verifica como a posição da câmera fotográfica afeta o cálculo da área de uma úlcera por pressão. Foi fotografada uma úlcera por pressão de grau III, com o eixo da câmera posicionado perpendicularmente à úlcera por pressão, às distâncias de 20 e 30 centímetros. Esse mesmo procedimento foi repetido com o eixo da câmera posicionado a $20^{\circ}$ e $30^{\circ}$ de inclinação. As imagens foram recortadas preservando-se apenas a úlcera por pressão, a pele sadia e o objeto padrão. Posteriormente, foram processadas pelo software 'Idrisi' para cálculo de área por classificação computacional. Os resultados mostraram que a posição da câmera fotográfica interfere no cálculo da área e que a menor alteração ocorreu com o eixo da câmera posicionado perpendicularmente à úlcera por pressão.

Descritores: Úlcera por Pressão, Fotografia, Processamento de Imagem, Medidas de Área.

\section{The position of the photographic camera influences the computerized calculation of the area of pressure ulcer?}

The analysis area of pressure ulcers through computer processing of images has been used as a mean of quantifying the evolution of wounds and responses to treatments. This article examines how the position of the photographic camera affects the calculation of the area of a pressure ulcer. It was photographed a pressure ulcer grade III, with the axis of the camera positioned perpendicular to the pressure ulcer, at distances of 20 and $30 \mathrm{~cm}$. This same procedure was repeated with the axis of the camera positioned at $20^{\circ}$ and $30^{\circ}$ tilt. The images were cut preserving only the pressure ulcer, skin healthy and standard object. They were later processed by the software 'Idrisi' for area calculation by computer classification. The results showed that the position of the camera interferes in the calculation of the area and that the smallest change occurred with the axis of the camera positioned perpendicular to the pressure ulcer.

Descriptors: Pressure Ulcers, Photography, Image Processing, Measures of Area

\section{La posición de la cámara influye en el cómputo informático de la zona de la úlcera por presión?}

El área de análisis de las úlceras por presión a través del procesamiento informático de imágenes se ha utilizado como un medio de cuantificar la evolución de las heridas y las respuestas a los tratamientos. Este artículo examina cómo la posición de la cámara afecta al cálculo de la superficie de una úlcera por presión. Se ha sido fotografiada una úlcera por presión grado III, con el eje de la cámara en posición perpendicular a la úlcera por presión, a distancias de 20 y $30 \mathrm{~cm}$. Este mismo procedimiento se repitió con el eje de la cámara situada a $20^{\circ}$ y $30^{\circ}$ de inclinación. Las imágenes fueron cortadas conservar sólo la úlcera por presión, objeto de la piel sana y por defecto. Fueron procesados posteriormente por 'Idrisi' el software para el cálculo del área de clasificación de equipo. Los resultados mostraron que la posición de la cámara se inmiscuye en el cálculo de la zona y que el más pequeño cambio se produjo con el eje de la cámara en posición perpendicular a la úlcera por presión.

Descriptores: Las úlceras por Presión, Fotografía, Procesamiento de Imágenes, Las Medidas del Área.

\section{INTRODUÇÃO}

U Icera por pressão (UP), também conhecida como escara é uma área localizada de necrose tissular, desenvolvida quando um tecido mole é comprimido entre uma proeminência óssea e uma superfície dura ${ }^{(1)}$.

Segundo o National Pressure Ulcer Advisory Panel, a prevalência de UP em hospitais nos Estados Unidos da América varia de 3\% a $14 \%$, aumentando para $15 \%$ a $25 \%$ em casas de repouso. Autores de um estudo realizado em um hospital universitário brasileiro, apontam uma porcentagem do número de casos apresentados de UP de $41,0 \%$ em unidade de terapia intensiva geral, 39,5\% em clínica cirúrgica e de $42,6 \%$ em clínica médica(2,3).

Os locais mais acometidos são as regiões da pele onde existe uma menor quantidade de tecido muscular e próximas a proeminências ósseas como sacro, grande trocânter, escápula, maléolo lateral, coluna torácica, calcanhares, occipital, joelhos, tuberosidades isquiáticas e epicôndilos laterais ${ }^{(1,4)}$.

A pressão contínua sobre a pele, seja por curto período de tempo e maior intensidade, seja por longo período e pequena intensidade, leva a fenômenos isquêmicos associados à deficiência de nutrientes e oxigênio, gerando hipoxia, edema,

1 Acadêmicas do Curso de Fisioterapia da Universidade Católica de Brasília-UCB.

2 Enfermeiro. Mestre em Ciências da Saúde. Docente da UCB.

3 Enfermeiro. Doutor em Administração. Docente da UCB.

4 Enfermeiro. Doutor em Ciências da Saúde. Docente da Escola Superior de Ciências da Saúde da Secretaria de Estado de Saúde do Distrito Federal. 
inflamação e morte celular ${ }^{(4-6)}$. Também está descrito que pressões entre 60 e $580 \mathrm{mmHg}$ no período de 1 a 6 horas podem causar uma úlcera. Além disso, forças de cisalhamento e fricção podem contribuir para o seu desenvolvimento, principalmente em pacientes com alterações de consciência e sensibilidade ${ }^{(4)}$.

A resistência tissular à pressão e à isquemia depende da natureza dos próprios tecidos e pode ser influenciada pela habilidade dos vasos sanguíneos, colágeno e fluído intersticial em redistribuir a pressão aplicada na superfície do tecido para a estrutura do esqueleto ${ }^{(7)}$. 0 tecido muscular é mais sensível à pressão e à isquemia do que a pele, dessa forma, quando ocorre lesão de pele em UP, uma grande área de tecido muscular também estará comprometida ${ }^{(7)}$.

As UPs podem ser classificadas de acordo com a profundidade, em relação à extensão da parede tissular envolvida, em graus de I a IV, sendo que o grau I manifesta-se como uma área definida de hiperemia persistente; o grau II como lesão parcial que compreende a epiderme, parte da derme ou ambas; o grau III como perda cutânea de espessura total envolvendo lesão ou necrose do tecido subcutâneo e o grau IV com destruição de todas as camadas da pele, tecido subcutâneo e muscular ${ }^{(6,8)}$.

A classificação dos tecidos do leito das UPs pode ser feita pela observação direta ou pela captação de imagens por meio de sistemas digitais, nos quais a ferida poderá ser classificada em três cores: a cor vermelha identifica tecido de granulação

Figura 2 - Imagem original captada com 0 grau de inclinação e $20 \mathrm{~cm}$ de distância da UP

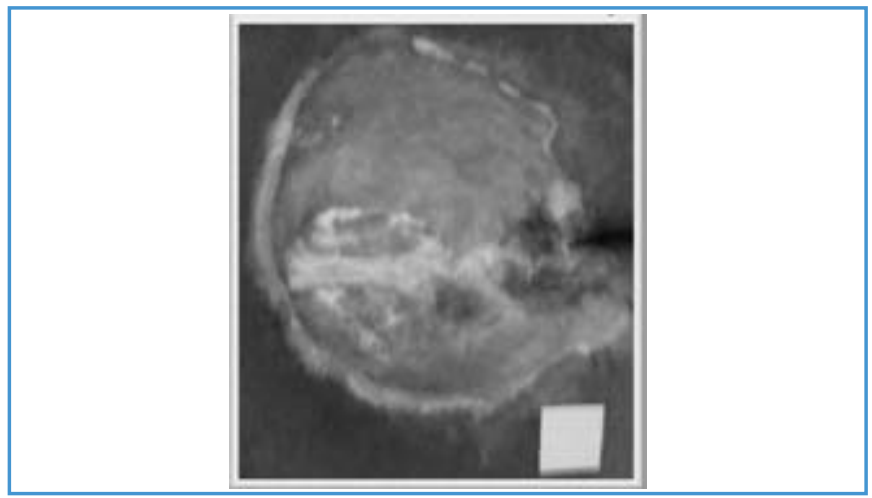

Figura 4 - Imagem do realce do objeto padrão

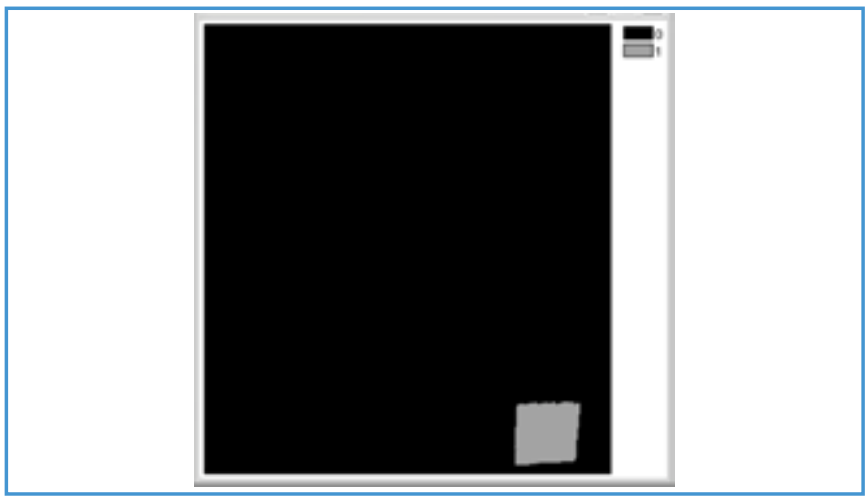

Figura 1 - Representação esquemática da posição da câmera

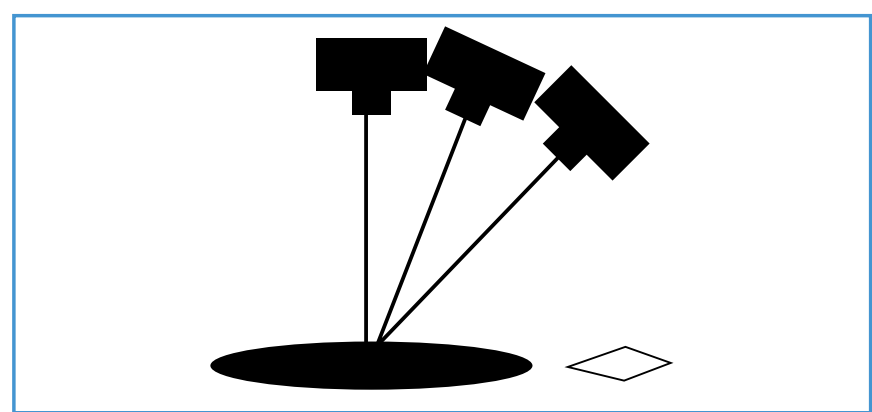

saudável e limpo, a cor amarela determina a presença de exsudato e a cor preta indica presença de tecido necrótico. Pode-se, ainda, encontrar um misto dessas três cores, nesse caso, a ferida será classificada quanto à cor predominante observada em seu leito ${ }^{(6,9)}$.

A determinação da largura, comprimento, profundidade $e$ formação de túneis completam e concluem a classificação de uma ferida ${ }^{(6)}$. Para tanto, instrumentos de avaliação têm sido desenvolvidos a partir da necessidade dos serviços e dos profissionais de saúde em montar um histórico mais preciso do paciente, auxiliando na elaboração de um plano de tratamento efetivo ${ }^{(10)}$. A área da ferida pode ser obtida por medidas simples, porém pouco precisas como régua, decalque em material

Figura 3 - Imagem da banda vermelha dessa UP

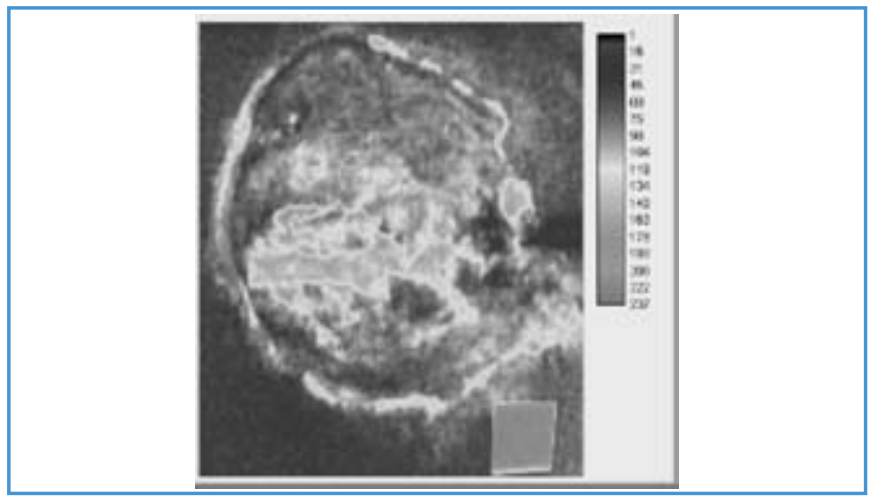

Figura 5 - Imagem da classe UP mais objeto padrão resultante da classificação Isoclusta

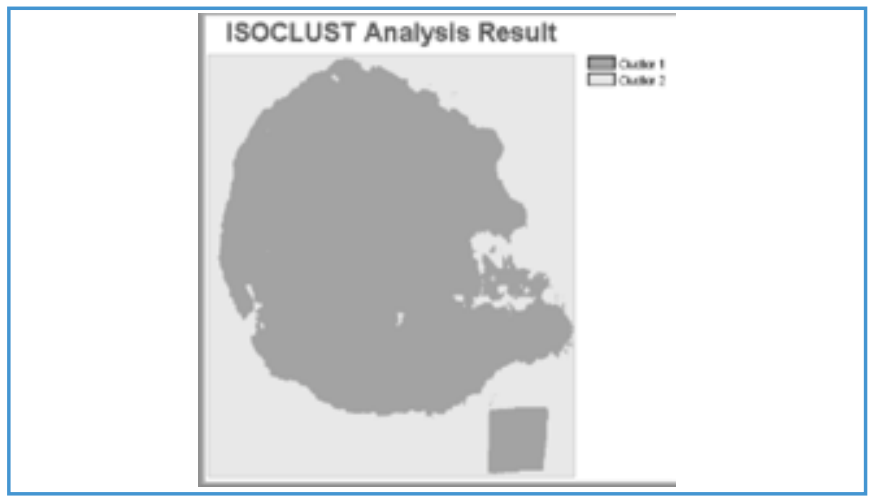


Figura 6 - Áreas da UP em diferentes inclinações e distâncias

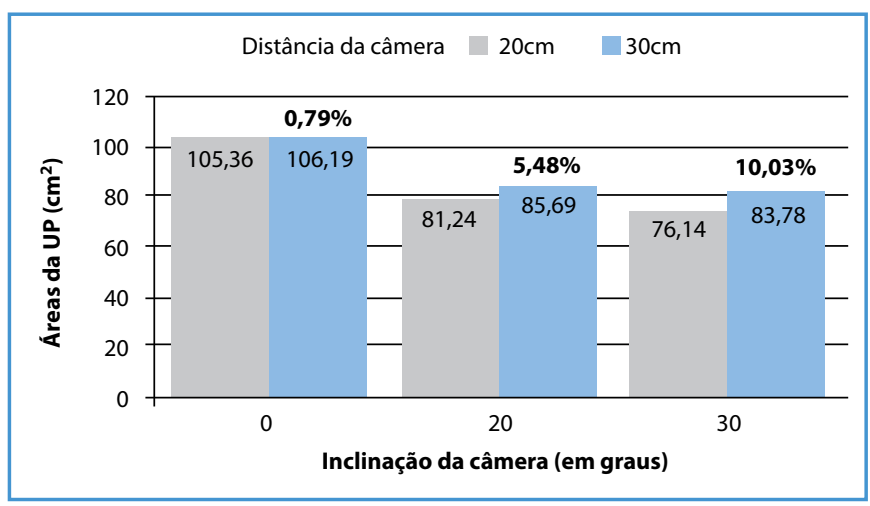

transparente, fotografias, ou por métodos mais precisos, como o uso de análise computadorizada por meio de fotografias digitais ${ }^{(8,10-15)}$.

O avanço tecnológico tem permitido maior acesso a câmeras digitais e a sistemas computadorizados devido à maior disponibilidade e ao baixo custo. Dessa forma, a análise fotográfica por meio de sistemas computadorizados vem sendo bastante utilizada para avaliação e acompanhamento das UPs ${ }^{(10,13)}$.

Mendes $^{(11)}$, quantificando os efeitos da aplicação do laser no processo de cicatrização de UP, fez uso da fotografia para o registro e posterior cálculo de área por meio do software AutoCAD 14 com o objetivo de acompanhar o comportamento das feridas. Perez ${ }^{(14)}$ acompanhou o tratamento de úlceras de perna por meio de fotografia para analisar quantitativamente cada tecido encontrado no interior da ferida, utilizando algoritmos de visão computacional.

Pires ${ }^{(15)}$ utilizou a fotografia digital para acompanhamento e observação direta da evolução das úlceras venosas crônicas quanto à área e quanto à qualidade do tecido das feridas, submetidas a tratamento com uso da estimulação elétrica com corrente de alta voltagem.

Medeiros $^{(10)}$ empregou a fotografia digital para avaliar imagens de feridas por meio de sistemas computacionais, com intuito de desenvolver um instrumento de avaliação não invasivo que permitisse uma visualização da evolução do tratamento aplicado pelos profissionais de saúde.

Os artigos anteriormente citados não descreveram se utilizaram controles de posicionamento da câmera para captação das imagens das UPs. Determinados autores tiveram a preocupação de padronizar a distância e o ângulo de incidência da fotografia com objetivo de evitar prováveis erros na aquisição da imagem ${ }^{(13)}$. Entretanto, a captação de imagens com esse controle requer dispositivo de fixação e padronização que envolve custo e também a necessidade de maior habilidade do operador da câmera.

Recentes tecnologias têm sido propostas para análise de feridas, como a avaliação de feridas crônicas em três dimensões com base na integração geométrica, cromática e térmica ${ }^{(16)}$, a utilização de equações diferenciais parciais para modelagem geométrica de feridas ${ }^{(17)}$, o estudo comparativo entre as técnicas Visitrak e fotografias ${ }^{(18)}$, o uso da câmera digital para avaliação tridimensional de feridas cutâneas ${ }^{(19)}$, a confecção de um sistema de imagem óptico e tridimensional da ferida e a avaliação da fotografia digital em úlceras por pressão na fase III(20).

O objetivo deste artigo foi investigar a influência da posição da câmera fotográfica no cálculo computadorizado de área de UP.

\section{MATERIAIS E MÉTODOS}

Estudo transversal no qual foram registradas, no dia 25/05/2007, seis fotos digitais de uma UP plana (Grau III) em região sacral do paciente LA, sexo masculino, 60 anos, portador de hemiplegia à esquerda e atrofia cerebral devido a acidente vascular encefálico ocorrido há 20 anos. $O$ consentimento para a realização das fotografias foi obtido por meio de uma autorização de uso de imagem, pelo seu acompanhante, depois de devidamente orientado quanto ao objetivo do estudo, e com assinatura de duas testemunhas.

As imagens foram adquiridas com uma câmera fotográfica digital da marca Kodak, modelo Easyshare, com resolução de dois megapixels. Para aferição da área, foi colocado um objeto padrão de quatro $\mathrm{cm}^{2}$ de cor azul em área não lesada, dentro do campo visual. A câmera foi posicionada com eixo perpendicular à superfície da UP, a distâncias de $20 \mathrm{~cm}$ e $30 \mathrm{~cm}$, as quais foram escolhidas aleatoriamente. Em seguida, esse mesmo procedimento foi repetido com o eixo da câmera posicionado a $20^{\circ}$ e $30^{\circ}$ de inclinação em relação à normal, com o objeto padrão posicionado mais próximo da câmera (figura 1).

As imagens foram recortadas preservando apenas a UP, o objeto padrão e a pele sadia adjacente (figura 2). Essa imagem foi processada em três bandas de cores correspondentes ao sistema RGB e escolhida a banda de melhor destaque do objeto padrão, nesse caso a banda vermelha (figura 3). O objeto padrão foi isolado para que sua área fosse calculada (figura 4). Em seguida foi emitida uma tabela com a quantidade de pixels correspondente à área do objeto padrão. A imagem inicial foi submetida ao classificador não supervisionado Isoclust que a limitou em duas classes, sendo a classe 1 a área do objeto padrão e da UP e a classe 2 a pele sadia adjacente (figura 5). Foi emitida uma nova tabela com a quantidade de pixels correspondente às áreas dessas duas classes. Obteve-se a área da UP após a subtração da área do objeto padrão.

Posteriormente foi feita a tabulação dos dados em planilha EXCEL com conversão da quantidade de pixels em área $\left(\mathrm{cm}^{2}\right)$ e construção do gráfico de barras contendo as áreas calculadas (figura 6).

\section{RESULTADOS E DISCUSSÃO}

De acordo com a figura 6, observa-se que, aumentando a inclinação da câmera, ocorreu a diminuição da área de todas as medidas porque, quando se inclina a câmera, os pontos mais distantes da câmera ficam mais próximos um dos outros, diminuindo a imagem do objeto, nesse caso, a UP; ao contrário do que acontece com os pontos da figura mais próxima da câmera, nesse caso o objeto padrão. Dessa forma, para maiores inclinações sempre ocorrerá uma diminuição da área da UP(21,22).

Ainda de acordo com a figura 6, em todas as situações, quando se distanciou a câmera, observou-se um aumento da área, o que se explica pela redução da distorção presente em fotos tiradas a curta distância. A distorção entre a parte central e 
a lateral do campo visual de fotos tiradas mais próximas é mais intensa do que para fotos tiradas a maiores distâncias ${ }^{(22-24)}$.

A figura 6 mostrou ainda que, para maiores inclinações, o aumento da distância da câmera influencia no aumento da área, porque minimiza a distorção causada pela inclinação, permitindo uma melhor visualização dos pontos da imagem, observando-se que em $30^{\circ}$ obteve-se uma maior variação de área (10,03\%) ao passo que na posição perpendicular obteve-se uma menor variação $(0,79 \%)^{(22-24)}$.

\section{CONCLUSÃO}

Os resultados demonstraram que o cálculo computadorizado da UP sofre influência da posição da câmera fotográfica.
Verificou-se que a menor variação de área aconteceu no eixo perpendicular da câmera em relação à UP, sendo esse o melhor posicionamento para o registro de fotografias para posterior avaliação e acompanhamento pelos profissionais de saúde, mesmo que se altere a distância. No aumento da inclinação do eixo da câmera em relação à normal, a superfície da UP distorce o cálculo da área para menos.

Sugere-se que estudos futuros estipulem limites de variação da posição da câmera, com o objetivo de se obter distorções aceitáveis no cálculo da área de UP. Esse cuidado possibilita uma captação de imagem de boa qualidade, com baixo custo e acessível aos profissionais de saúde, possibilitando seu uso com maior frequência.

\section{Referências}

1. Costa IG. Incidência de úlcera de pressão e fatores de risco relacionados em pacientes de um centro de terapia intensiva [Internet]. [citado em 2007 Mar 03]. Disponível em: http://www.teses.usp.br/teses/ disponiveis/22/22132/tde-09032004-084518/

2. Blanes L, Duarte IS, Calil JA, Ferreira LM. Avaliação clínica e epidemiológica das úlceras por pressão em pacientes internados no Hospital São Paulo. Rev Assoc Med Bras. 2004;50:182-7.

3. Rogenski NMB, Santos VLCG. Estudo sobre a incidência de úlceras por pressão em um hospital universitário. Rev Latinoam Enferm. 2005;13:474-80. 4. Costa MP, Sturtz G, Costa PPC, Ferreira MC, Filho TEPB. Epidemiologia e tratamento das úlceras de pressão: experiência de 77 casos. Acta Ortop Bras. 2005;13:124-33.

5. Jorge AS, Dantas SRPE. Abordagem multiprofissional do tratamento de feridas. São Paulo: Atheneu; 2005.

6. Hess CT. Úlceras de pressão. Tratamento de feridas e úlceras. Rio de Janeiro: Reichmann \& Affonso Ed.; 2002. p. 79-106.

7. Leite VBE, Faro ACM. Identificação de fatores de risco associados às úlceras por pressão em indivíduos paraplégicos relacionados às atividades de lazer. Acta Fisiatr. 2006;13(1):21-5.

8. Ministério da Saúde (BR). Secretaria de Políticas de Saúde. Departamento de Atenção Básica. Manual de condutas para úlceras neurotróficas e traumáticas [Internet]. [citado em 2007 Mar 18].

Disponível em: http://portal.saude.gov.br/portal/arquivos/pdf/ manual_ feridas final.pdf.

9. Flanagan M. Uma estrutura prática para a determinação de ferimentos 2: métodos. Rev Tec Enferm. 1997;117:22-6.

10. Medeiros GCF. Uso de texturas para acompanhamento da evolução do tratamento de úlceras dermatológicas [Internet]. [citado em 2007 Mar 03. Disponível em: http://www.teses.usp.br/teses/disponiveis/22/22132/tde09032004-084518

11. Mendes AFO. Avaliação do laser, com o comprimento de onda $670 \mathrm{~nm}$, no processo de cicatrização de úlceras de pressão no paciente lesado medular [dissertação]. Brasília: Universidade de Brasília; 2002.

12. Santos VLCG, Azevedo MAJ, Silva TS, Carvalho VMJ, Carvalho VF. Adaptação transcultural do Pressure Ulcer Scale for Healing (PUSH) para a língua portuguesa. Rev Latinoam Enferm. 2005;13(3):305-13.
13. Souza MGP, Quintiliano P, Trindade L, Santana L, Sá E, Guadagnin R. Recognition of texture and area of decubits ulcers throught computer vision. Pattern Recognit Imag Analys. 2005;15:586-8.

14. Perez AA. Segmentação e quantificação de tecidos em imagens coloridas de úlceras de perna [dissertação]. [citado em 2007 Mar 03]. Disponível em: http://biblioteca.universia.net/html_bura/ficha/params/ id/4071701.html

15. Pires EJ. Fisioterapia na cicatrização e recuperação funcional nos portadores de úlceras de hipertensão venosa crônica: uso da estimulação elétrica com corrente de alta voltagem [Internet]. [citado em 2007 Mar 03]. Disponível em: http://biblioteca.universia.net/html_bura/ficha/params/ id/4071701.html

16. Barone S, Paoli A, Razionale V. Assessment of chronic wounds by threedimensional optical imaging based on integrating geometrical, chromatic, and thermal data. Pisa: Department of Mechanical, Nuclear, and Production Engineering, University of Pisa; 2010.

17. Ugail H. Partial differential equations for modeling wound geometry. In: Gefen A. Bioengineering research of chronic wounds a multidisciplinary study approach. Bradford: Book Series Studies in Mechanobiology, Tissue Engineering and Biomaterials, University of Bradford; 2009.

18. Treuillet S, Albouy B, Lucas Y. Three-dimensional assessment of skin wounds using a standard digital camera. IEEE Trans Med Imaging. 2009;28(5):752-62.

19. Chang AC, Dearman B, Greenwood JE. Techniques: visitrak versus photography. Adelaide, Australia: [s.n.]; 2011.

20. Bowling FL, King L, Fadavi H, Paterson JA, Preece K, Daniel RW, et al. An assessment of the accuracy and usability of a novel optical wound measurement system. Diabet Med. 2009;26(1):93-6.

21. Ball GH, Hall DJ. A novel method of data analysis and Ppattern classification. Menlo Park, CA: Stanford Research Institute; 1965. 22. Watt A, Policarpo F. The computer Imag. UK: Addison-Wesley; 1998. p. 654-60.

23. Ammeraal L. Computer graphics for java programmers. [s.I.]: John Wiley \& Sons; 1998. p. 113-25.

24. Foley JD, van Dam A, Feiner SK, Hughes JF. Computer graphics: principles and practice. $2^{\text {a }}$ ed. USA: Addison-Wesley; 1996. p. 229-83. 